\title{
Vision 2030: Made in China?
}

\author{
Michael Mabe* \\ Ladysmith Associates, Oxford, United Kingdom
}

Good afternoon, and a big thank you to Arnoud for asking me to provide an endnote to APE's 15th anniversary conference.

Predicting the future is a fraught thing to do. I was asked in 2010 to predict the future of STM publishing by 2020 at the Association of Subscription Agents annual meeting. There I applied a strategic marketing planning technique to examine the trends that would influence the future, in that case 2020. A primary conclusion was that as we were in a world of digital objects that are infinitely reproducible and infinitely changeable this would create all sorts of consequences for scholarly publishing. Back then I thought that copyright would no longer be simple or easy to administer. Business models based on reproduction and distribution would be increasingly under threat, and that permanence and trust in authority were challenged because of the intrinsic nature of digital objects.

Now the big problem about making predictions is that when you arrive at that future it becomes clear what you overlooked. In this case, very shortly after the ASA conference, I missed foreseeing the collapse of the ASA itself! Its conference has been resurrected as Researcher2Reader but the ASA is no more. A caveat there for anyone trying to make predictions: you can get it wrong very easily.

The strategic planning tool used in the 2010 talk (and using again today) is usually called PEST. It was invented by Francis Aguilar of the Harvard Business School, although he didn't use that exact acronym at the time [1].

\section{PEST}

What does PEST stand for? The acronym stands for Political, Economic, Sociological and Technological, and represents the four foci of any environmental analysis of the external environment within which businesses are operating. In the scholarly publishing world: politics is about public priorities, about the policies of universities and research funders; economics is about business models, expenditure mechanisms in the market; the sociological dimension is about attitudes deriving from the technology shift but mainly those of our core market, the scholars themselves, how their behaviour patterns stay the same or change; and lastly technology issues and how they arise, new applications, and hardware. It was clear ten years ago that culture and utility issues essentially drive the behaviour of scholars more than any other factor, and this is still true now. Lots of research has been done over the last decade illustrating this point $[2,6,13,14,15]$.

\footnotetext{
*E-mail: mamabe@btinternet.com.
} 


\section{Sociology}

There have been several articles published over the last few years about why it is that the scholarly publishing system has not changed as much as the early internet pioneers thought that it would [4,7]. One of the reasons I believe is that the journal system, the fundamentals of it, were created to satisfy human factors. In other words, the things that journals do - register, certify, disseminate, archive, and help people navigate to content - all derive from human needs. They do not derive from technology; they do not derive from how you do stuff. They derive from what people want to do, and why they want to do it. All of this has been achieved over the last three centuries by the management of the brand identity of a journal, otherwise known as the journal title, via which all the journal functions are delivered.

Now the journal paradigm is not without its challengers. Technology has allowed the different journal functions to be separated out (first suggested by Smith [16]), as we heard at various points during some of the keynotes yesterday. But the challengers do not deliver all the functions simultaneously in one act yet. Having said that, there are subject areas where the system is creaking. Why is this happening? It is not due to the model being wrong; it is due to the nature of the disciplines themselves. Where you have disciplines with very large co-authorship levels, the idea of being an author is diluted: if you're just one author, you care enormously about what happens to your paper and how it works; if you're one of a thousand, you might not care nearly so much. It is also about peer review: how peer review is conducted in areas like mathematics and in theoretical subjects is very different to experimental subjects.

In theory subjects and mathematics, (high level researcher) readers could just read a paper and decide whether they think it is right or wrong. In the case of economics and computer science, there is also a different way of working, not like the rest of the scholarly world. So, in mathematics, economics, and computer science we are seeing deviations from the paradigm [8]. We must not forget that the journal paradigm only applies in those areas where journals are regarded as the most important method of discourse. That is not true for many areas, especially in the arts and humanities, where books have always played the most important role. Perhaps the biggest challenge to the paradigm now is could some of the journal functions be done automatically through data collection, and through artificial intelligence? This I think will be a key question in the 2020s leading to 2030.

\section{Technology}

Many believed that the technology revolution was going to result in a much more radical shift, and many of them believed this for personal anecdotal reasons. You would hear views expressed in conferences along the lines of "Well, my kids do X. They're digital natives, blah, blah, blah. Therefore, everything's going to be different when the new generation of researchers comes along". I think this misunderstands the nature of cohorts, and how they evolve through time. A quote from the Bible illustrates this issue quite well:

When I was a child, I spake as a child...: but when I became a man, I put away childish things.

- Corinthians 13:11

It is clear this idea of cohorts and age appropriateness is not fully understood by marketeers: BBC executives look at the age profile of its main talk radio channel BBC Radio Four and fear that a relative lack of young audience members is going to kill it off over time. Whereas in fact I suspect what they are observing is the cohort effect: people migrate from the pop station Radio One to Radio Two as they become older, and then they start listening to speech radio, which is Radio Four. This is an age/professionalisation differentiation, and we should perhaps expect to see that in our own arena as well. 
Lots of research has been done, the most recent of it by CIBER, on early career researchers [11]. The conclusion of all these studies has been that young scholars are more conservative than their older peers, and this is because their main objective is to get published, and they actively dislike policies that interfere with what they see as their primary goal.

\section{Politics}

What about the politics angle? JC Burgelman pointed out in his keynote that the 15-20 years of strife that we have had between the activists and others in the discussion about open access has resulted in more heat than light, and in particular moral simplicities being juxtaposed against pragmatic complexity.

One of the things I observed over this time period was that there were essentially four slogans that had been created out of the political collision between digital objects and the wider internet activism of Silicon Valley:

- $\mathbf{E}$ is free. In other words, if you have electronic objects which have no physicality, some conclude that this must mean they have no value, so they ought to be free

- Yours is mine. If these things are "free" then there is no problem giving what you have to someone else. This is the drive behind sharing of digital objects whether they are yours or not that led to Napster and sits behind many more recent services of dubious legality.

- (Intellectiual) property is theft. The counterculture movement of the 1960 s believed that property is theft, and there has been a strong tradition among copyleftists to think the same about IP. This encourages the previous two slogans to be applied more generally.

- Public funding means public access. This slogan has been well deployed by those that think all research papers should be free. We heard a version of it in the keynote presentation by Schulze yesterday. This is simplistic, because if this were true, then by analogy the citizens of Tokyo who hope to attend the 2020 Olympics should expect to do so without paying to get in. And that is not going to happen. Funding of research is just that: it funds the research; only rarely does it also fund the publication.

The lack of understanding of these factors and frustration of the activists that so little has happened, or when it has, it is perceived as too slow, has led to precipitate and potentially not very effective public policy actions where analysis has not prevailed, and unwillingness to listen to nuance has resulted in diktat over discussion.

\section{Economics}

The economic component is still very stable: journal growth has remained remarkably consistent over a very long period, probably nearly three centuries, and this is almost entirely due it being driven by the growth in the number of researchers. We are faced, however, with dealing with a whole variety of different business models. But one trend that is clear is the move away from publishing business models based on library funding, and towards direct research funding. And of course, this means that there will be even more roles for funders and governments than there have been in the past. 


\section{Summary of the PEST for 2030}

Putting all this together for 2030, as it was for 2020, the sociology of the research culture is the dominant force trumping technology influences. The publishing paradigms are strong, even though under pressure in some disciplines. Technology has aided business model fragmentation, and that is going to continue, and we have seen the challenges that are necessarily posed by artificial intelligence entrants. Digitization, the move to malleable objects and infinite reproducibility, means we cannot control objects once they have been created and therefore traditional copyright and business models based on distribution, reproduction and ownership probably do not have a future.

Subscription models and content control through copyright are probably going to be untenable by 2030 . The OA pay-to-publish models should become the norm, however in this context we must bear in mind the politics and the economics. The collision of internet attitudes, the support for openness has resulted, at the moment, in a mixed model environment. But to move further than the present mix will require solutions to the intractable issues of an uneven distribution of money in a system that straddles several national jurisdictions. As JC Burgelman said in his keynote: "There's enough money there but it's in the wrong places".

Publishers will have to help stakeholders come up with a mechanism by which there are no winners or losers inhibiting an open access conversion, and that is going to be difficult. When I spoke with the European Commission OA Envoy Robert-Jan Smits in 2018 about how we could accelerate OA adoption I said we needed to address this problem. In my judgement one way forward would be to trial a European version of the Californian Pay-it-forward approach that decouples institutions from directly paying to publish OA through the use of an intermediary that would receive current subscription spending [12]. He decided not to pursue this, and we got Plan S instead.

\section{China}

Lin Peng from China Science Press in his keynote spoke about what I think is the biggest element in our future - China. China is the world's largest economy since 2015. It has the largest share of R\&D spending, an astonishing $37.6 \%$ of the world total, and has become the largest producer of papers, $19 \%$ of world output versus the US on $18 \%$. It ranks second in terms of the overall share of citations. It ranks third in terms of the share of top cited publications [18]. In 2010, 44\% of Chinese students majored in science, technology, and medical subjects, versus $14 \%$ in the United States, and that in China, scientists earned more than doctors and lawyers. This must tell us something rather fundamental about the future and how it is going to develop.

There are broad political initiatives going on in China to bolster and achieve economic pre-eminence. The drive for economic and national self-sufficiency is essentially one of the key components of Xi Jinping's approach to running his country. Examples are:

- Belt and Road Initiative. This is essentially the creation of a new Silk Road for economic development with financial incentives and loans for third parties [9].

- Made in China 2025 initiative. This was an understanding there was a need to have action to secure manufacturing, transformation, and pre-eminence in 10 different sectors [17].

- Thousand Talents Program. The Chinese State Council became aware that science was a route to innovation, and development, and technology. They were keen on introducing an initiative to try to 
attract members of the (academic) Chinese diaspora back to the homeland, largely with financial incentives [19].

Last year this spawned a desire to look at the next phase of how they could develop their own academic environment. Several different organizations, the Chinese Association of Science and Technology, the National Science Foundation of China, the Chinese Academy of Sciences, the Ministry of Education, the Ministry of Science and Technology, got together to brainstorm how they could improve Chinese scientific journals. A report was published on this in August 2019 [10].

This report is still not available in an official English translation, though informal ones exist, and was commented upon in Nature in December 2019 [5]. The report recognized that the current Chinese journal publishing industry is relatively old fashioned; from my experience the distinction between what an editor does, and what a publisher does is poorly understood. The Chinese authorities are very concerned about quality, recent fraud issues and the image this gives. They are aware of the author and referee rings that have happened. They want to make China a publishing powerhouse, and the slogan "Chinese journals for Chinese science" while not explicitly used comes to mind. It is important to see this in the context of China's recent history: the sorts of sensitivities that one can imagine in a country that was pulled apart between 1840 and 1950, by foreign interference, the overthrow of the Qing dynasty, the fragmentation of warlords, the invasion by Japan and the Nationalist/Communist civil war. Following on from the report, an action plan was formulated [3] in which the top 250 English language journals were ranked into three tiers, and the top tier, which is 25 titles, is going to receive between one and 5 million renminbi each to attract international submissions. Merely throwing money at the issue is not necessarily going to be the answer. Quality and international collaboration are intertwined, and it is not clear from this report whether they have recognized that they would need to have that.

Now there are issues that immediately arise from this. One of them is that science is international, not national. What would Chinese biochemistry involving just Chinese researchers mean? That is not how the world of scholarship works. So, this approach already falls into the nationalistic error made by politicians when thinking about scholarship. Secondly, would non-Chinese authors really be attracted? The track record would suggest otherwise. What the Chinese really need to do is work on modernising their publishing techniques such as how you take a journal that is failing and turn it around, by looking at issues connected with the type of authors and what really attracts them. In the short term without help I do not think they are going to succeed.

So, for the 2020s onwards, it seems to me the biggest question we face, in addition to the analysis that I gave you earlier, is twofold: Will Chinese researchers and journals participate in the existing largely Western academic publishing world? Or is the dominance of their numbers and the funding in China so great that the rest of the world is subsumed into a new global model with its centre of gravity in the East? How we address this will probably be the biggest influence on what happens in the next decade.

\section{Reflections on 40 years in scholarly publishing}

Reflecting on 40 years in academic publishing, the themes touched on in this conference and also the things identified in the PEST analysis above, my experience tells me that future success will be about engagement and how we practice it.

(1) Engage with China. We must engage with China, but how matters as much as what. In the Far East, and this applies in Japan as well as in China, personal face-to-face relationships are important: you 
must have regular in person meetings. You cannot just expect to fly in, sign a deal, and fly out. This was my experience over five years of trying to get involved with the Chinese publishing world for STM.

Attitudes matter. You need to be constructive and honest. You should not flatter, but also avoid being arrogant. Do not try telling a civilization that is 5,000 years old what they have got wrong. But on the other hand, you should not, to use their phrase, kowtow to them. You should be prepared to be honest, but you also should be polite, and you need to recognize that in China especially, but to a certain extent in the rest of the East, face and saving face is really important. Do not place them in a position where they will feel they have lost stature.

(2) Engage with researchers and rediscover the core publishing skills. As far as our type of publishing is concerned, one size, as we keep hearing, does not fit all, but I am not sure whether we actually act on it. Research is tribal. It is a myriad of little academic villages that all have their own rules and behaviours, and we need to recognize this in the ways in which we interact with them. Probably the core skill in publishing is relationship management: it is vital, and it requires empathy and understanding of researchers to build trust. As another speaker said, "We must understand our customers". And in this context the researchers are very much the most important customer. How have we reached the stage where perhaps this is not the case? The digital transition upended our publishing culture. The need to convert a paper industry to essentially a digital one over a five-year period resulted in platforms and solutions and technology dominating the mix. We need to have staff that understand the human factors that I mentioned earlier, the politics and sociology with a small $\mathrm{P}$ and a small $\mathrm{S}$ that make particular communities want to publish, want to edit, want to referee, want to work with the publishers that they see as part of their community, an "us" not a "them". And we have to make sure our staff have the knowledge and skills to engage meaningfully with the specialist communities they interact with.

As far as it goes, when we do apply tools to them, we have to make sure that instead of imposing technology on them, we need to work more closely with them to make what they want to do easier and quicker. We need to remember that digital publishing technology is a hugely important tool, but it is a tool, it is not the master. And from a personal point of view, having published now quite a few papers, it was a real eye opener to me of what being an author was like. So, every time you think your authors are being a bit unreasonable, I think you should probably go away and try publishing a paper yourselves with your own systems and see how you feel about it.

(3) Engage with the consequences of digitization and open access. Digitization and OA have been the dominant themes since at least 2000. It is pretty clear to me that the digital transition and digital objects will ultimately kill the traditional models and ultimately copyright, I think. But the barriers to $100 \%$ OA do exist. JC Burgelman talked about them, but I think we need to be realistic and understand that having the right amount of money but in the wrong places creates huge, huge challenges. The barriers to $100 \%$ OA are political rather than economic. All stakeholders need to work together to help that be overcome.

The STM publishing world has had a great past, a thriving present, and potentially can have an equally great future. For this to happen, though, we will need to take heed of the issues raised in this talk, but especially engagement with China and a return to the core publishing skills that made scholarly publishing such a success in the last seventy-five years. 


\section{References}

[1] Francis J. Aguilar, Scanning the Business Environment. Macmillan, NY, 1967.

[2] Berkeley Study, Assessing the Future Landscape of Scholarly Communication. Available at: https://escholarship.org/ uc/cshe_fsc, 2010.

[3] Chinese Sci-Tech Journals Excellence Action Plan. Available at: http://news.sciencenet.cn/htmlnews/2019/11/433140. shtm, 2019.

[4] Michael Clarke, Why Hasn't Scientific Publishing Been Disrupted Already? Scholarly Kitchen. Available at: https:// scholarlykitchen.sspnet.org/2010/01/04/why-hasnt-scientific-publishing-been-disrupted-already/, 2010.

[5] David Cyranoski, China spends millions to boost home-grown journals, Nature 576: (2019), 346-347.

[6] ITHAKA S+R with JISC and RLUK UK Survey of Academics 2015. Available at: https://sr.ithaka.org/publications/uksurvey-of-academics-2015/, 2016.

[7] Michael Mabe, UKSG 35th Annual Conference, Glasgow Conference debate: why hasn't the journal changed more as a result of the internet? Available as video at: http://zeeba.tv/so-why-hasn $\% \mathrm{e} 2 \% 80 \% 99 \mathrm{t}$-the-journal-changed-more-as-aresult-of-the-internet/, 2012.

[8] Adrian Mulligan and Michael Mabe, The effect of the internet of researcher motivations, behaviours and attitudes, $J$. Documentation 67: (2011), 290-310.

[9] OECD, The Belt and Road Initiative in the global trade, investment and finance landscape. in: OECD Business and Finance Outlook 2018. Paris, 2018, doi:10.1787/bus_fin_out-2018-6-en.

[10] Opinions on Deepening Reforms and Cultivating World-class Scientific and Technological periodicals. http://www. xinhuanet.com/science/2019-08/19/c_138320888.htm, August 2019.

[11] PRC (2016, 2017, 2018) Publishing Research Consortium Early Career Researchers: Harbingers of Change Years One, Two and Three. Available at: http://ciber-research.eu/harbingers.html.

[12] Pay-it-forward, Final report of the Pay-it-Forward Project. Available at: https://www.library.ucdavis.edu/wp-content/ uploads/2018/11/ICIS-UC-Pay-It-Forward-Final-Report.rev_.7.18.16.pdf, 2016.

[13] RIN (2009) E-journals: Their use, value and impact. Available at http://www.rin.ac.uk/system/files/attachments/Ejournals-report.pdf, 2009.

[14] RIN (2011) E-journals: Their use, value and impact final report. Available at http://www.rin.ac.uk/system/files/ attachments/Ejournals_part_II_for_screen_0.pdf, 2011.

[15] RIN (2012) Physical sciences case studies. Available at https://www.iop.org/publications/iop/2012/file_53558.pdf, 2012.

[16] J.W.T. Smith, The deconstructed journal: A new model for academic publishing, Learned Publishing 12: (1999), 79-91.

[17] State Council PRC (2020): Made in China 2025. Retrieved from: http://english.www.gov.cn/2016special/madeinchina 2025/.

[18] STM Report, Available at: https://www.stm-assoc.org/2018_10_04_STM_Report_2018.pdf, 2018.

[19] Thousand Talents Program, Retrieved from: http://www.1000plan.org.cn/en/, 2020. 